\title{
Aged strain Japan's medical system
}

Japan's public medical insurers spent a record $¥ 23.8$ trillion (approximately US\$238 billion) helping keep Japan's rapidly ageing population alive and healthy in 1994. Japan, which has the world's highest average life expectancy rate (83 years for women, 77 for men), now spends almost 7 percent of its national income on medical care, according to the latest Ministry of Health and Welfare statistics.

A large increase of just over 10 percent in the cost of caring for Japan's elderly pushed up medical care expenditure by 6.3 percent in just one year, leading to last year's record figure. The ageing popu-
Japan, which has the world's highest life expectancy rate, now spends almost $7 \%$ of its national income on medical care ....
One of the main issues is how to reduce Japan's apparent dependence on prescription drugs. In 1994, public medical insurers paid out an astonishing $\$ 72$ billion for prescription drugs, accounting for almost 30 percent of total medical expenditure. This far exceeds most western countries. Prescription drugs account for 20 percent of France's medical costs; Germany spends 17 percent and the United States 11 percent.

The ministry is also considering raising insurance premiums and getting the elderly to contribute more towards their medical costs, as well as promoting home medical care. Japan's national lation and Japan's dwindling birth rate are putting severe strains on the public health insurance system, which has provided universal coverage since 1961 . In 1994, more than one-third of all health insurance payments were spent treating patients over the age of 70, in a year when Japan's population grew by the smallest amount on record. It now costs on average $\$ 71,000$ a year to treat each patient over 70 .

Japan's greying society (like that of many other nations) makes it more and more difficult each year for the public health insurance system to keep the finely balanced equilibrium between beneficiaries and contributors, which is essential to maintaining a healthy functioning system.

During the past 25 years, a huge demographic shift has occurred in Japan with the percentage of people over the age of 65 doubling from 7 percent to 14 percent of the population. It took 115 years for a similar transition to take place in France and 45 years in Britain and West Germany. Last year it cost Japan $\$ 81$ billion to treat its elderly and these costs are bound to escalate. The recent slow-down in the economy is exacerbating the problem as the revenue from insurance premiums has fallen while medical costs continue to rise.

The Ministry is now considering how to reform the health insurance system to cope with Japan's rapidly changing environment but is facing the extremely difficult task of trying to maintain universal coverage while continuing to provide efficient, high-quality medical care. medical insurance system, which is extremely complicated, can be broadly divided into two groups: employees' insurance, which covers most employees, and community-based insurance, which covers those employed in agriculture, forestry and fisheries, the self-employed, and others.

Both are regulated and subsidized by the government but are managed by various government organizations and private-sector associations. The insured pay a monthly premium based on their income, which covers between 70 and 90 percent of their medical costs, depending on which scheme they belong to. It also covers their dependents but to a lesser extent.

The elderly, who are defined as all those over the age of 70 , or those between the ages of 65 and 70 who are permanently bedridden or disabled, however, have to pay $\$ 10$ per month for any outpatient treatment they receive and $\$ 7$ per night if hospitalized. This does not include meals or extras. More than one-third of Japanese hospitals do not provide adequate nursing care and many patients employ their own nurses, which adds to the expense. The true cost of health care in Japan and its effect on the Japanese economy is undoubtedly much more significant than the ministry's public medical care insurance figures indicate.

RICHARD NATHAN Tokyo

\section{DID YOU KNOW?}

Multidrug-resistant TB in UK

The first outbreak

of hospital-

acquired

IMAGE

resistant

tuberculosis has

occurred in the

UK. The cluster

of cases,

involving five

UNAVAILABLE

FOR COPYRIGHT REASONS

Mycobacterium

tuberculosis: the culprit

patients with the

human immunodeficiency virus (HIV), was

reported at the HIV unit of the Chelsea and

Westminster Hospital in London.

The index case, a patient who had spent some time in Portugal, was admitted to the unit in April and died in June, the communicable disease report CDR Weekly states (vol. 5, no. 34). A spokeswoman for Chelsea \& Westminster Hospital said the patient was admitted with a fever and was isolated two days later after tests suggested infection with tuberculosis.

Six HIV-positive patients shared a hospital bay with the index patient for the first two days. Of them, four have developed multidrug-resistant tuberculosis, one has escaped infection and is well, and the sixth has since died of AIDS. The spokeswoman said the four patients are being successfully treated. "We now believe it is unlikely that further cases will occur from this present outbreak," she said. The strain of Mycobacterium tuberculosis isolated from all five patients is resistant to isoniazid, rifampin, rifabutin, pyrazinamide, clofazamine and ethionamide but sensitive to six other antibiotics.

SHARON KINGMAN London

\section{Do as I say, not as I do}

Despite the US Food and Drug

Administration's decision to classify nicotine as a drug, cigarettes are still on sale at Japan's Ministry of Health and Welfare. At the ministry's offices in central Tokyo, where some 2,000 Ministry of Health and Welfare officials work, visitors can find at least 17 vending machines, which offer an extensive choice of up to 30 different brands of cigarettes, including Winston and Camel, as well as popular Japanese brands such as Mild Seven. According to government statistics, 43,721 people died from respiratory-related cancers in Japan in 1993.

RICHARD NATHAN Tokyo 